\title{
Effects of different suture patterns and materials on healing of incised skin wounds in cattle
}

\author{
MA Islam, NS Juyena*, RN Ferdousy and MAA Mamun \\ Department of Surgery and Obstetrics, Faculty of Veterinary Science, Bangladesh \\ Agricultural University, Mymensingh-2202, Bangladesh
}

\begin{abstract}
Studies on skin closure techniques are scarce in veterinary practice. The aesthetic result of a skin suture is hardly considered in ruminants. This study was designed to compare the morphological characteristics and outcome of incised skin wounds closed with three suture patterns using two suture materials. Simple interrupted (SI), cross mattress (CM) and horizontal mattress (HM) suture patterns were used with nylon and silk to close incised skin wounds. A total of 54 surgical wounds were made in nine cattle. Follow-up information was obtained up to day 30 postoperatively. Area of wound, elevation of suture line from the skin surface, width of suture area and contraction length per week was recorded. Silk caused more tissue reaction and suture marks than nylon. Simple interrupted suture produced good apposition but showed suture marks. Horizontal mattress caused marked tissue swelling, inflammation, sloughing of cutting edges due to prominent eversion and strangulation of cutting edges and produced prominent scar. Cross mattress produced good apposition with sufficient eversion of cutting edges and good cosmetic appearance with fewer suture marks. It is suggested that cross mattress pattern with nylon could be a better choice for closing skin wounds in ruminants. This study could help veterinary surgeons to consider appropriate suture technique and materials for skin closure. (Bangl. vet. 2014. Vol. 31, No. 1, 27 - 37)
\end{abstract}

\section{Introduction}

Wound is the disruption of the cellular and anatomic continuity of a tissue (Bennett, 1988). Skin wounds are more common in ruminants, and cause economic loss and reduce quality of leather. Good wound management provides a minimal scar (Hollander and Singer, 1999). Wounds may be approximated with sutures, staples, clips, skin closure strips, or topical adhesives. Sutures are used to bring the edges of a wound in close apposition (Kumar and Kumar, 2002). Sutures initially provide the mechanical strength to seal the wound and protect it from pathogens (Yang et al., 2009).

Different suture materials and suture techniques are used and affect healing. Generally, monofilament non-absorbable suture materials are used with simple interrupted and horizontal mattress sutures for skin closure because they induce little foreign body response (Smeak, 1992). The choice of suture technique mainly depends on the type and location of the wound, the thickness of the skin, the degree of tension,

\footnotetext{
* Corresponding author:- E-mail: juyenahabib@yahoo.com
} 
and the desired result. The healing process can be affected by the amount of suture material used, the suture type, the suture pattern, and the amount of tension on the suture (Maticic, 2005). Studies have shown the holding power of various suture methods (Gal et al., 2006 \& 2009). The suture material could be a decisive factor on the initial holding power and later gap stiffness. The majority of studies in human surgery focus on the aesthetic nature of wound healing with minimum infection rates (Adams et al., 2003). However, studies on skin closure techniques are scarce in veterinary practice. This study was designed to compare the morphological characteristics and outcome of incised skin wounds closed with three suture patterns, simple interrupted (SI), cross-mattress (CM) and horizontal-mattress (HM), using two suture materials, nylon and silk, to compare healing effects of suturing patterns.

\section{Materials and Methods}

The study was conducted from November 2011 to May 2012.

\section{Animals}

Nine apparently healthy indigenous cattle (Bos indicus) were used. Body weight and ages of animal ranged from 80-120 kg and 1- 3 years, respectively. Cattle were well maintained and dewormed with albendazole (Almax ${ }^{\circledR}$, Square pharmaceuticals Ltd, Dhaka, Bangladesh) before starting the experiment.

\section{Experimental design}

A total of 54 surgical wounds were made in nine cattle. Cattle were divided into three groups with three animals in each group (Table 1).

Table 1. The experimental design

\begin{tabular}{l|l|c|c|c|c}
\hline Group & \multicolumn{1}{c|}{ Suture Pattern } & Nylon & Silk & $\begin{array}{c}\text { No. of } \\
\text { Animals }\end{array}$ & $\begin{array}{c}\text { No. of } \\
\text { wounds }\end{array}$ \\
\hline SI & Simple Interrupted & 9 & 9 & 3 & 18 \\
CM & Cross Mattress & 9 & 9 & 3 & 18 \\
HM & Horizontal Mattress & 9 & 9 & 3 & 18 \\
\hline
\end{tabular}

Follow-up information was obtained up to day 30 after surgery. Swelling, elevation of suture line from the skin surface, and width of sutured area were recorded.

\section{Surgical technique}

Clinical examination was performed to ensure that the animal was apparently free from infection or infestation. A vertical incision was made in flank and neck region (Fig. 2), each $5 \mathrm{~cm}$ long and $0.5 \mathrm{~cm}$ deep, under local anaesthesia with $2 \%$ lidocaine hydrochloride (Jasocaine ${ }^{\circledR}$; Jayson Pharmaceuticals, Bangladesh). In each wound $3 \mathrm{ml}$ Jasocaine ${ }^{\circledR}$ was given subcutaneously by local infiltration. In each animal, one suture pattern was used with one suture material. 
To place a simple interrupted suture, the needle with nylon or silk entered one side of the wound and penetrates well into the dermis of one cutting edge and then passes through opposing side of the wound. (Fig. 3a \& b). To place a cross mattress suture, a cross-stitch is formed by placing two throws of a simple suture, then tying the two ends diagonally across the external segment to form an X-shaped pattern (Fig. 4a \& b). To place a horizontal mattress suture, the needle is inserted into skin $5 \mathrm{~mm}$ from the edge of the wound. The needle is then passed subcutaneously toward the opposing wound edge where it enters at the same level in the subcutaneous tissue. After exit the opposing wound edge through the epidermis equidistant from the point of insertion, the needle re-enters the skin on the same side at the same distance from the wound edge. The needle is then passed subcutaneously to the side of initial penetration and tied with reinforced surgeon's knot.

Three wounds were made at a time in one side and repeat operation was done at least 15 days later in another place. All sutures were placed $8 \mathrm{~mm}$ apart. Distance between needle placement and border of cutting edge was $5 \mathrm{~mm}$ (Fig. 1). For all wounds, knots were tied with three throws (Reinforced surgeon's knot).

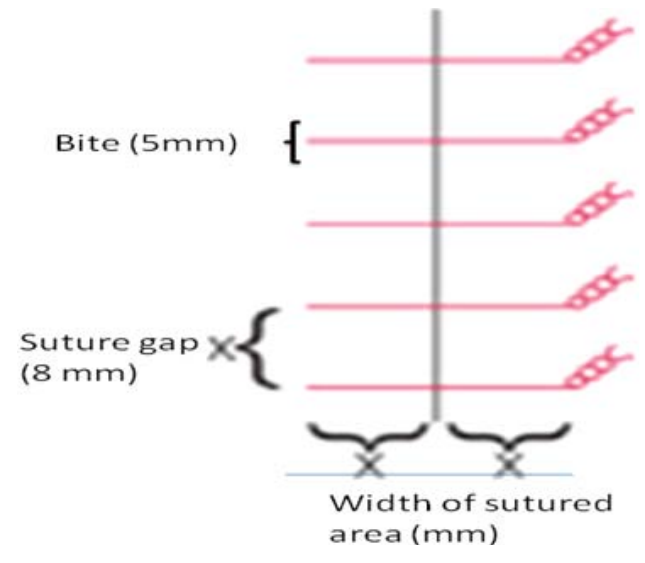

Fig. 1. Schematic presentation of suture technique

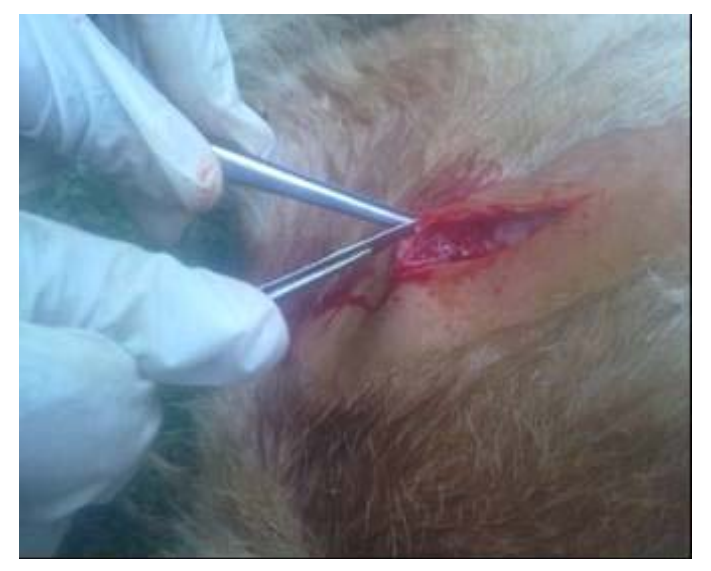

Fig. 2. Wound preparing

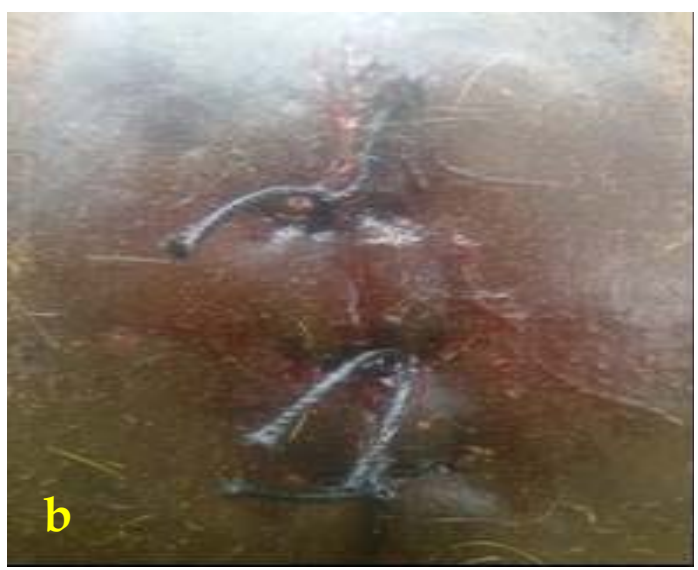

Fig. 3. Simple interrupted pattern with nylon (a) and silk (b) 

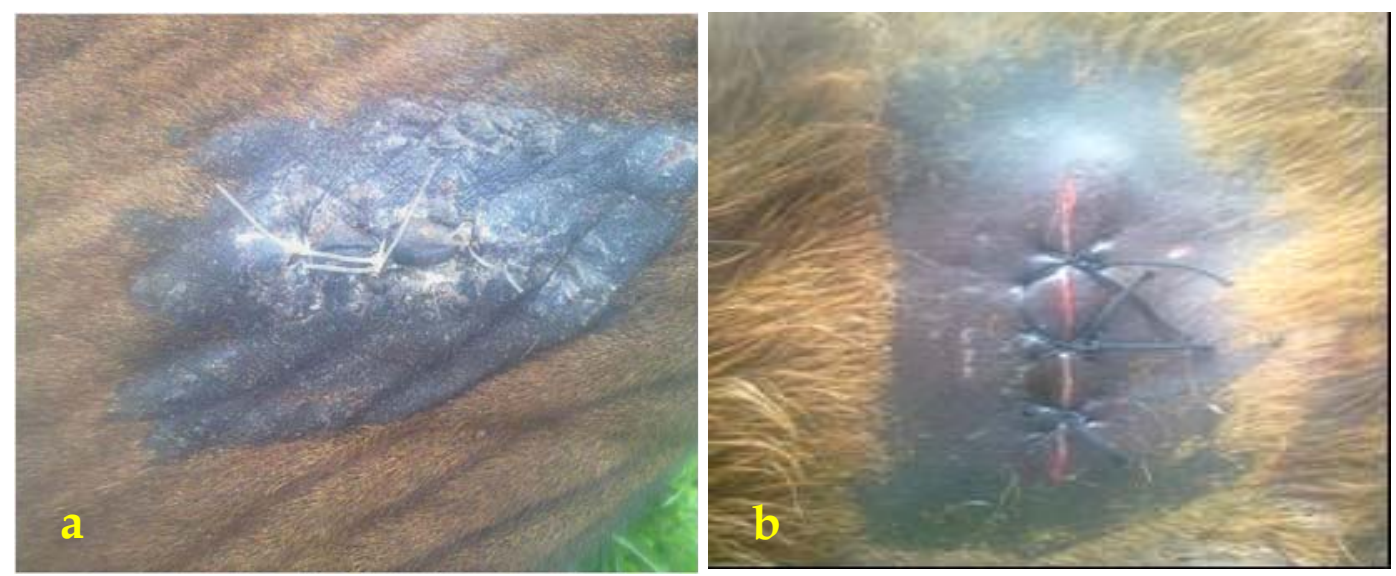

Fig. 4. Cross mattress pattern with nylon (a) and silk (b)
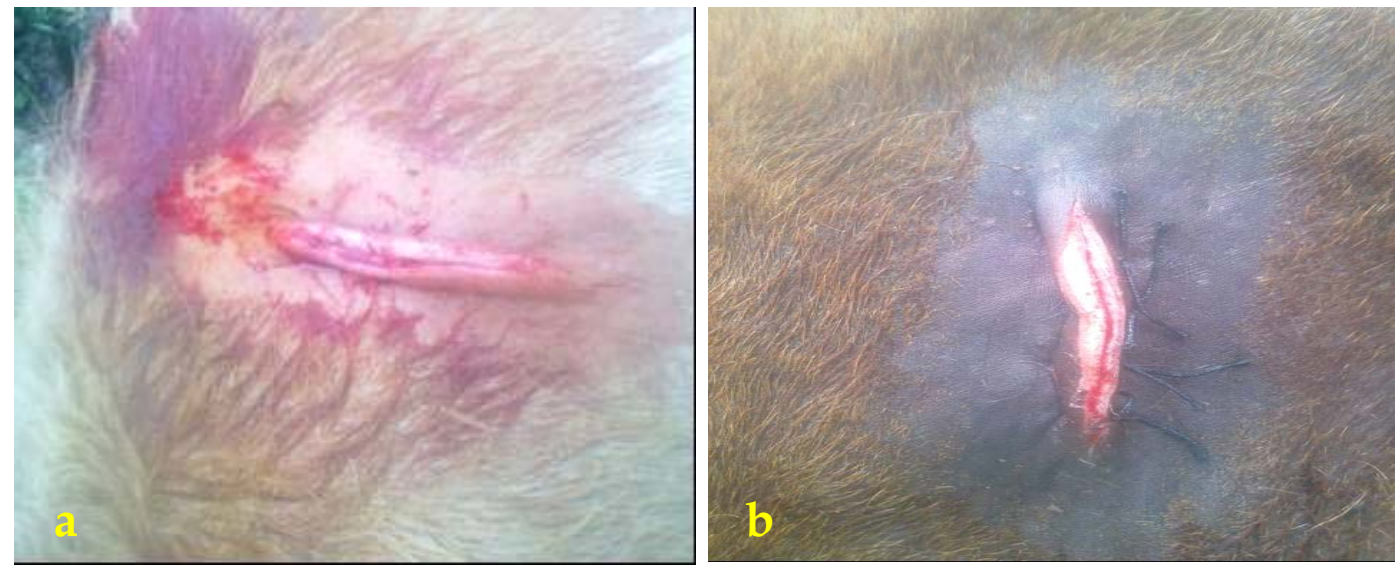

Fig. 5. Horizontal mattress pattern with nylon (a) and silk (b)

\section{Postoperative care}

After suturing, benzoin seal (Tincture Benzoin, MM chemicals, Bangladesh) was applied onto the sutured area. The animals were maintained carefully so as to avoid interference with granulation tissue formation.

\section{Observation of wounds}

Slide calipers were used to measure swelling area $(\mathrm{mm})$, elevation of suture line $(\mathrm{mm})$ and width of the sutured area $(\mathrm{mm})$. The progress of healing was monitored daily. A wound was assumed healed when cicatrization and pigmentation was found. Healing score was categorized as: Excellent- minimum inflammation, no exudation, no infection, no dehiscence, gradual decreasing of width of cutting edge (contraction length $2 \mathrm{~mm} /$ week). Good- minimum inflammation with little exudation, no dehiscence, gradual decreasing of thickness of cutting edge (contraction length 2 $\mathrm{mm}$ /week) were recorded. Fair- marked inflammation, presence of infection and exudation, contraction length $1 \mathrm{~mm} /$ week. 


\section{Statistical analysis}

All data were presented as mean \pm SEM. To compare data between groups one-way ANOVA analysis was performed. The data were analysed with SAS 12.5 software. Probability $\mathrm{P}<0.5 \%$ was considered statistically significant.

\section{Results and Discussion}

Swelling was observed up to three days after operation, then decreased gradually from day 3 (D3). Elevation of suture was recorded at day 7 (D7) after removal of sutures. There was no significant difference in swelled areas of wounds sutured by nylon and silk using SI and CM pattern. When HM was used, swelling was significantly greater with nylon that with silk $(\mathrm{P}<0.05)$. Among three patterns, more swelled area was observed in wounds closed with HM than with SI and CM, irrespective of suture material (Graph 1 \& 2). Elevation of suture area varied significantly $(\mathrm{P}<0.05)$ between nylon and silk within a single group. In all groups, elevation of sutured line was higher when nylon was used (Table 2).

When suture patterns were considered along with suture material, elevation of suture area was significantly $(\mathrm{P}<0.05)$ higher in wounds closed with $\mathrm{HM}$ than with $\mathrm{CM}$ (Graph 1 and 2). Similarly, wound contraction was lower in wounds sutured with CM than with SI and HM, irrespective of suture material (Graph 1 and 2). Contraction length did not differ significantly (Table 2).

Table 2. Parameters of wounds sutured with two suture materials using three suture patterns (Mean \pm SEM)

\begin{tabular}{|c|c|c|c|c|c|c|}
\hline $\begin{array}{l}\text { Suture } \\
\text { pattern }\end{array}$ & $\begin{array}{c}\text { Suture } \\
\text { material }\end{array}$ & $\begin{array}{l}\text { Swelling of } \\
\text { sutured } \\
\text { area }(\mathrm{mm})\end{array}$ & $\begin{array}{l}\text { Elevation of } \\
\text { suture line } \\
(\mathrm{mm})\end{array}$ & $\begin{array}{l}\text { Contraction } \\
\text { per week } \\
(\mathrm{mm})\end{array}$ & observation & $\begin{array}{l}\text { Healing } \\
\text { score }\end{array}$ \\
\hline \multirow[t]{2}{*}{ SI } & Silk & $11.5 \pm 0.5$ & $2.7 \pm 0.3^{a}$ & $1.5 \pm 0.3$ & $\begin{array}{l}\text { Infection, myiasis, } \\
\text { exudation (1) }\end{array}$ & Fair \\
\hline & Nylon & $11.6 \pm 0.5$ & $3.7 \pm 0.3^{b}$ & $1.6 \pm 0.3$ & No exudation & Excellent \\
\hline \multirow[t]{2}{*}{$\mathrm{CM}$} & Silk & $11.7 \pm 0.3$ & $2.4 \pm 0.1^{\mathrm{a}}$ & $1.5 \pm 0.2$ & $\begin{array}{l}\text { Inflammation, } \\
\text { wet suture line }\end{array}$ & Good \\
\hline & Nylon & $11.1 \pm 0.3$ & $3.2 \pm 0.1^{b}$ & $1.6 \pm 0.2$ & - & Excellent \\
\hline \multirow[t]{2}{*}{$\mathrm{HM}$} & Silk & $12.0 \pm 0.5^{\mathrm{a}}$ & $3.6 \pm 0.2$ & $1.5 \pm 0.3$ & $\begin{array}{l}\text { Inflammation, wet } \\
\text { suture line }\end{array}$ & Good \\
\hline & Nylon & $13.7 \pm 0.5 b$ & $3.7 \pm 0.2$ & $1.8 \pm 0.3$ & - & Excellent \\
\hline
\end{tabular}

$\mathrm{a}, \mathrm{b}$ indicate significant $(\mathrm{P}<0.05)$ difference between subgroups; SI- Simple interrupted; CM- Cross mattress; HM- Horizontal mattress 


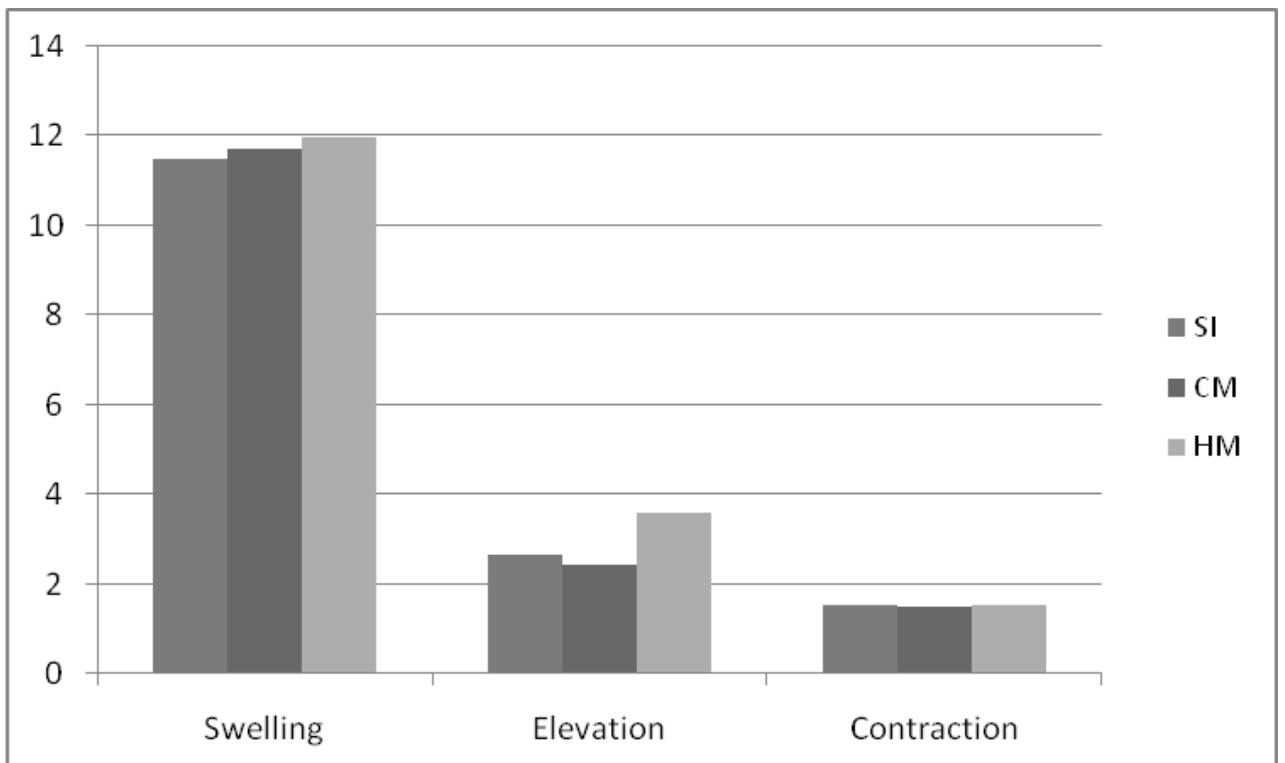

Graph 1. Swelling, elevation and contraction length of wounds sutured with silk using three patterns. SI- Simple interrupted; CM- Cross mattress; HM- Horizontal mattress

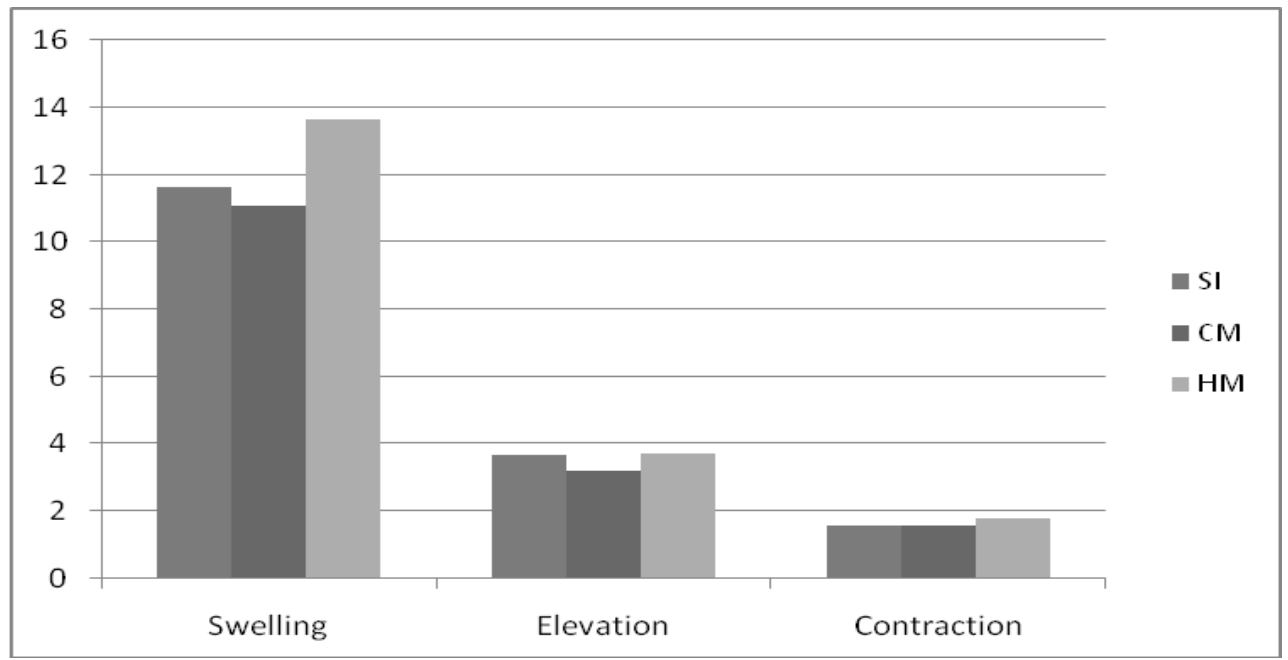

Graph 2. Swelling, elevation and contraction length of wounds sutured with nylon using three patterns. SI- Simple interrupted; CM- Cross mattress; HM- Horizontal mattress

Wounds closed with nylon using SI pattern had larger sutured area than with silk up to day $7(\mathrm{P}<0.05)$. Later, width of sutured line gradually decreased and variation was insignificant up to day 30 (Table 3). In CM group, no significant difference was observed between two subgroups at different times of observation (Table 3). In HM group, wounds closed with silk were wider than with nylon, except on day 3 when diameter was higher with nylon. Wounds closed with HM using silk and nylon were significantly wider at days 0,3 and 30 (Graphs 3 and 4). 
Table 3. Width (mm) of wounds sutured with two suture materials using three suture patterns (Mean \pm SEM)

\begin{tabular}{l|c|c|c|c|c|c|c}
\hline $\begin{array}{c}\text { Suture } \\
\text { patterns }\end{array}$ & $\begin{array}{c}\text { Suture } \\
\text { material }\end{array}$ & D0 & D3 & D7 & D14 & D21 & D30 \\
\hline SI & Silk & $6.6 \pm 0.3^{\mathrm{a}}$ & $7.6 \pm 0.3^{\mathrm{a}}$ & $7.7 \pm 0.4^{\mathrm{a}}$ & $6.3 \pm 0.3$ & $4.1 \pm 0.3$ & $3.1 \pm 0.1$ \\
& Nylon & $7.7 \pm 0.3^{\mathrm{b}}$ & $8.9 \pm 0.3^{\mathrm{b}}$ & $8.4 \pm 0.4^{\mathrm{b}}$ & $6.2 \pm 0.3$ & $4.6 \pm 0.3$ & $3.2 \pm 0.1$ \\
$\mathrm{CM}$ & Silk & $6.6 \pm 0.2$ & $7.3 \pm 0.2$ & $7.5 \pm 0.3$ & $5.8 \pm 0.3$ & $4.3 \pm 0.2$ & $3.0 \pm 0.1$ \\
& Nylon & $6.6 \pm 0.2$ & $7.6 \pm 0.2$ & $7.6 \pm 0.3$ & $6.3 \pm 0.3$ & $\bullet \pm 0.2$ & $2.7 \pm 0.1$ \\
$\mathrm{HM}$ & Silk & $8.2 \pm 0.4$ & $8.9 \pm 0.5^{\mathrm{a}}$ & $7.7 \pm 0.4$ & $6.3 \pm 0.3$ & $4.3 \pm 0.3$ & $3.1 \pm 0.2$ \\
& Nylon & $8.1 \pm 0.4$ & $9.4 \pm 0.5^{\mathrm{b}}$ & $7.6 \pm 0.4$ & $6.1 \pm 0.3$ & $3.7 \pm 0.3$ & $2.8 \pm 0.2$ \\
\hline
\end{tabular}

$\mathrm{a}, \mathrm{b}$ indicate significant $(\mathrm{P}<0.05)$ difference between subgroups of a group; SI- Simple interrupted; CM- Cross mattress; HM- Horizontal mattress; D- Day

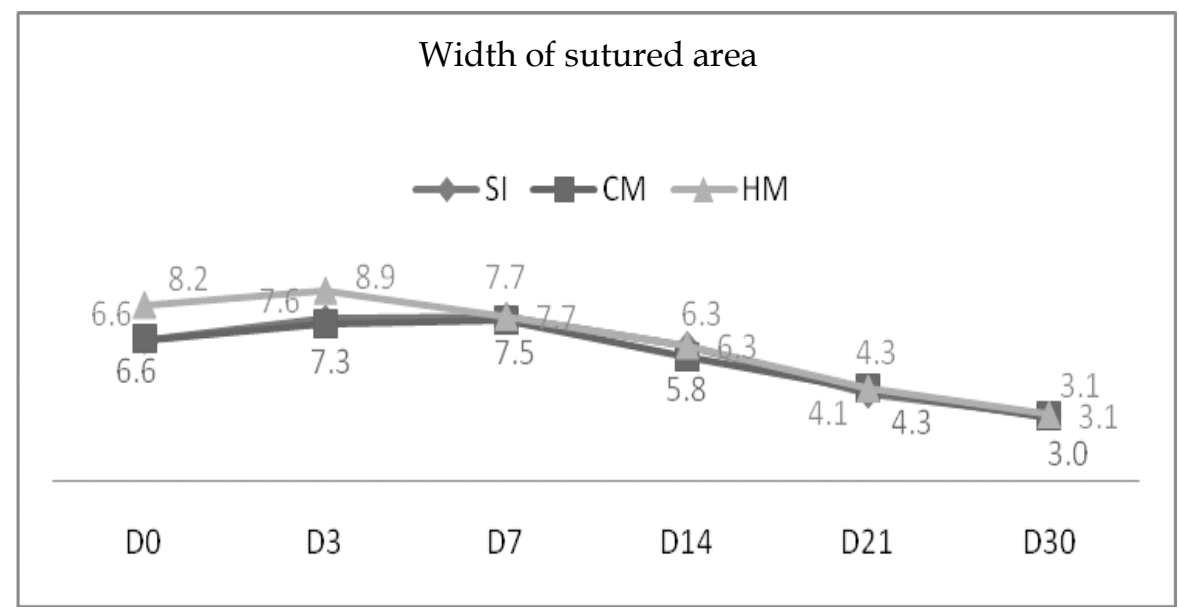

Graph 3. Width of wounds sutured with silk using three patterns from day 0 to day 30; SI- Simple interrupted; CM- Cross mattress; HM- Horizontal mattress

Fair to good healing was observed in wounds sutured with silk. In contrast, all wounds sutured with nylon, irrespective of suture pattern, maintained excellent healing score (Table 2). Marked improvement was noted within 24 hours and all signs of inflammation had resolved by the 7th day of treatment. Epidermal bridging was present in wounds closed with SI (Fig. 6.1) and this bridging gradually disappeared from day 7. Epidermal bridging was more prominent when SI was applied with silk. This study revealed visible suture marks in wounds closed with SI pattern: these were very marked in wounds closed with SI using silk (Fig. 6.2). Similarly, suture marks were observed in wounds (Fig. 7.2) closed by silk with cross mattress pattern: these marks disappeared gradually. Wounds closed with cross mattress using nylon showed less prominent suture marks (Fig. 7.1). We observed sloughing of cut edges (Fig. 8.1a) in wounds sutured with horizontal mattress within 14-21 days postoperatively and prominent scar on the wound surface (Fig. 8.2b). 


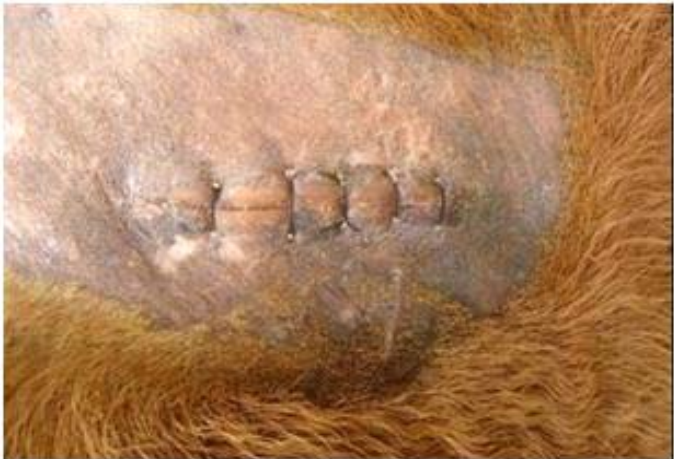

Fig. 6.1. Epidermal bridging in the simple interrupted suture with nylon

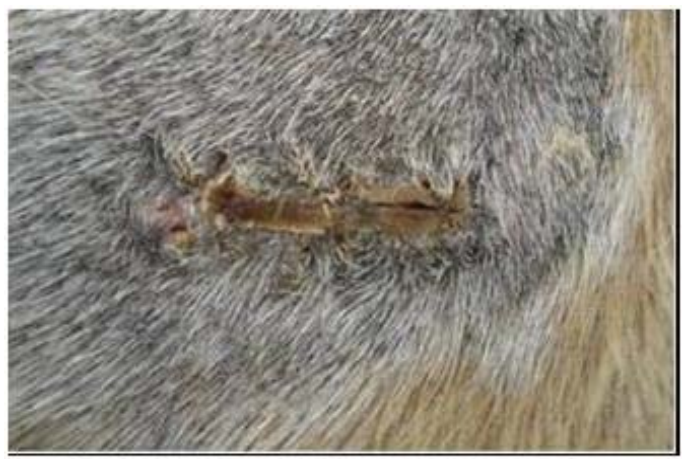

Fig. 7.1. Suture marks (arrows) with cross mattress suture using nylon

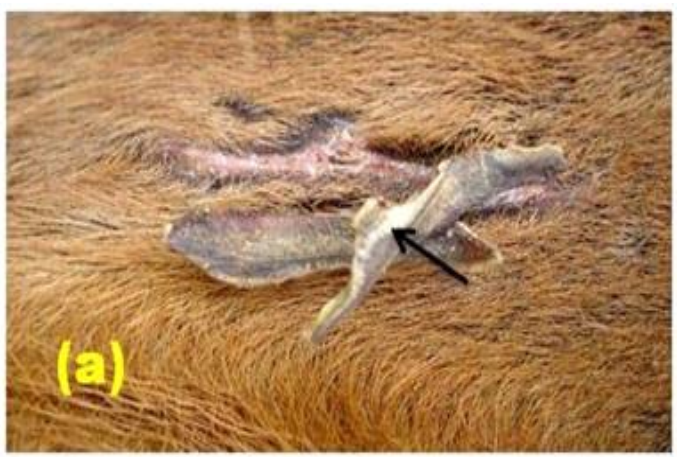

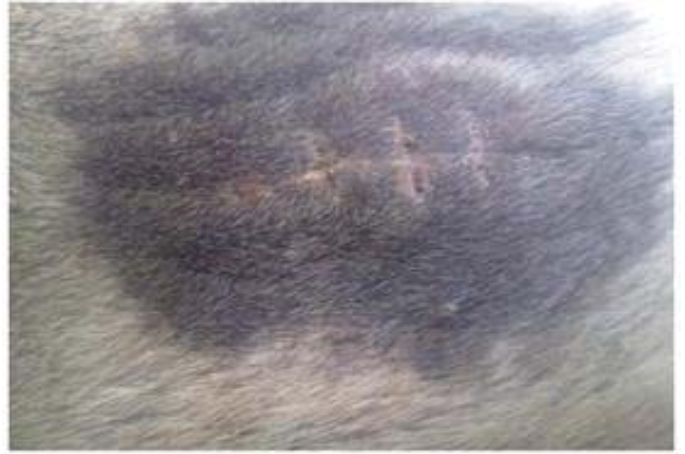

Fig. 6.2. Suture marks in the simple interrupted suture with silk

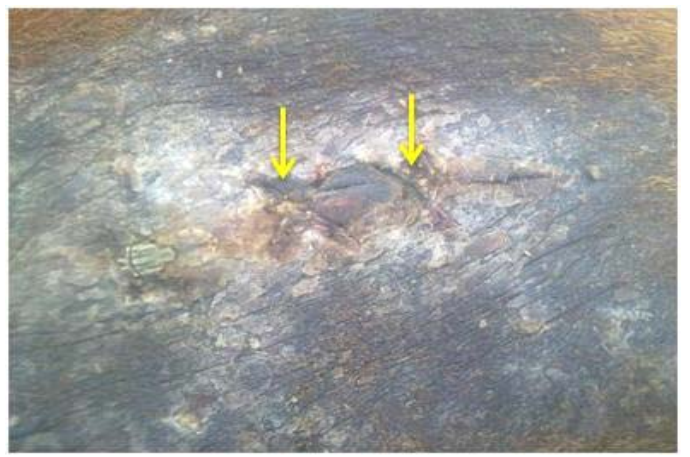

Fig. 7.2. Suture marks (arrows) with cross mattress suture using silk

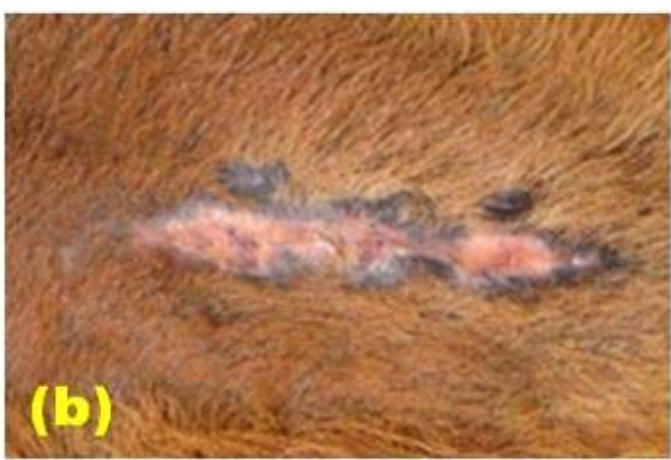

Fig. 8.1. Sloughing of cutting edges with Fig. 8.2. a scar was left with horizontal mattress horizontal mattress within 14-21days

This study sought to investigate some morphological characters of skin wounds closed by different suture materials and techniques. We observed more swelling in wounds sutured with horizontal mattress using either silk or nylon (Table 2) than with other suture techniques (Graph $1 \& 2$ ). This may have been due to the greater tissue handling 
required for suture placement, as well as the amount of suture material. Some studies have shown that local stress provided by sutures can cause inflammatory signs, change extracellular matrix synthesis, affect growth factor secretion and influence scar formation (Oguma et al., 2007).

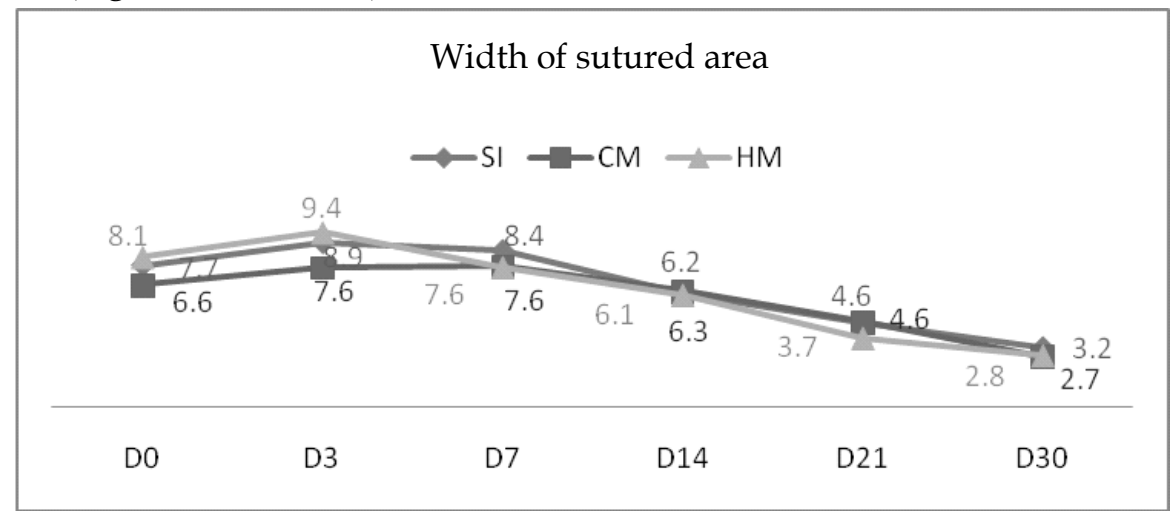

Graph 4. Width of wounds sutured with nylon using three pattern from day 0 to day 30; SI- Simple interrupted; CM- Cross mattress; HM- Horizontal mattress

Suture materials affect healing through their interaction with tissue and the diameter and length of suture, its physical construction and its chemical composition are also considered to influence healing (Boothe, 1998). Silk exhibits high capillarity, which increases the risk of infection. Its fibres hold blood which is an excellent medium for bacterial proliferation (Kumar and Kumar, 2002). Silk has been shown to wick bacteria into a wound, and significant tissue reactions are observed in many species (Wood et al., 1984; Denardo et al., 1996). Kudur et al. (2009) suggest that silk should not be used when the cosmetic appearance is important.

Skin closure with nylon irrespective of suture pattern produced excellent results. This result corresponds well with the findings of Yang et al. (2009). Nylon, a nonabsorbable monofilament suture, has the advantages of strength, pliability, lack of capillary action and inertness. Denardo et al. (1996) reported that monofilament nylon sutures were the most resistant to bacterial adherence when used to close wounds in the oral cavity of cats. From this study we could summarize that nylon is almost an ideal suture material for skin closure.

In Simple interrupted suture, suture marks and epidermal bridging are very common (Monheit, 1998; Adams et al., 2003). If simple interrupted suture is tied too tightly, it causes suture marks after postoperative oedema. When the suture is removed, the tract of the epithelial cells remains. Eventually, it may disappear, but some may form keratin and suture marks may persist (Ethicon wound closure manual, 2012).

There was sloughing of cut edges (Fig. 8.1a) and thereafter, prominent scars (Fig. 8.2b) in wounds sutured with horizontal mattress 14-21 days postoperatively. Horizontal 
mattress sutures cause strangulation of the epidermis because of pressure (Adams et al., 2003) and wound edge necrosis if tied too tightly. Kumar and Kumar (2002) reported that the main disadvantages of horizontal mattress are greater scar formation and delayed healing as a result of prominent eversion.

Our study reveals cross mattress as one of the best suture patterns to ensure eversion of wound with good apposition. This finding agrees with the report of Kumar and Kumar (2002) who stated that cross mattress as a tension suture, is stronger than simple interrupted and brings the tissue into close apposition without much eversion of wound edges.

Our study could help veterinary surgeons to consider appropriate suture pattern and suture material for skin closure. Histopathological study would be necessary to understand the effect of these suture techniques and two suture materials on the healing of skin wounds.

\section{References}

Adams B, Jamshaid AM, David A, Wrone MD, Alam MM 2003: Techniques for cutaneous sutured closures, variants and indications. Journal of Veterinary Surgery 30 311-314.

Bennett RG 1988: Selection of wound closure materials. American Academy of Dermatology 18 619-637.

Boothe HW 1998: Selecting suture materials for small animal surgery. Compendium Continental Education and Practice in Veterinary 20 155-162.

DeNardo GA, Brown NO, Trenkabetha,S, Marretta S 1996: Comparison of seven different suture materials in the feline oral cavity. Journal of the American Animal Hospital Association 32 164-172.

Gal P, Toporcer T, Vidinsky B, Hudak R, Zivcakand J, Sabo J 2009: Simple interrupted percutaneous suture versus intradermal running suture for wound tensile strength measurement in rats. European Journal of Surgical Research 43 61-65.

Gal P, Toporcer T, Vidinsky B, Mokry M, Novotny M, Kilik R, Smetana K, Galand T, Sabo J 2006: Early changes in the tensile strength and morphology of primary sutured skin wounds in rats. Folia Bioligy 52 109-115.

Hollander JE, Singer AJ 1999: Laceration management. Annual Emergency of Medicine 34 356.

Kudur MH, Pai SB, Sripathi H, Prabhu S 2009: Sutures and suturing techniques in skin closure. Indian Journal of Dermatology 75 425-434.

Kumar A, Kumar A 2002: A suture material and techniques by Tyagi RPS, Singh J, In: Ruminant surgery 6th edn. CBS Publishers \& Distributors New Delhi- 110002 59-73.

Maticic D 2005: Skin closure in dogs with polypropylene and polyglactin 910. Veterinary archives 75 383-390. 
Monheit GD 1998: Wound closure and suture technique, in JL Ratz, In: Textbook of Dermatologic Surgery. Philadelphia, PA, Lippincott-Raven., 117-125.

Oguma J, Ozawa S, Morikawa Y, Furukawa T, Kitagawa Y, Uedaand M, Kitajima M 2007: Knot-tying force during and wound healing in the gastrointestinal tract, Journal of Surgical Research 140 129-134.

Smeak DD 1992: Buried continuous intradermal suture closure. Compendium Continental Education and Practice in Veterinary 14 907-919.

Wood DS, Collins JE, Walshaw R 1984. Tissue reaction to nonabsorbable suture materials in the canine linea alba: a histological evaluation. American Animal Hospital Association $2039-44$.

Yang CS, Yeh CH, Chen MY, Jiang CH, Suand FC, Yeh ML 2009: Mechanical evaluation of the influence of different suture methods on temporal skin healing. Journal of Dermatological Surgery 35 1880-1885. 